\title{
Spiritual Space or Theme Park? A Case of Postmodern Simulated Experience
}

\author{
GENEVIÈVE GAMACHE \\ Asian University for Women, 20/A MM Ali Road, Chittagong, Bangladesh \\ University of Malaya, Cultural Center, \\ 1st Floor Old Chancellery Building, 50603 Kuala Lumpur, Malaysia \\ genevieve.gamache@auw.edu.bd / genevieve@um.edu.my
}

Published online: 15 April 2017

To cite this article: Gamache, G. 2017. Spiritual space or theme park?: a case of postmodern simulated experience. KEMANUSIAAN the Asian Journal of Humanities 24(1): 99-119, https://doi.org/10.21315/kajh2017.24.1.5

To link to this article: https://doi.org/10.21315/kajh2017.24.1.5

\begin{abstract}
The small village temple Wat Rong Khun on the outskirts of Chiang Rai in northern Thailand is a modern artistic experiment created, at least partly, to attract both international and national tourists. As such, it is very successful - hundreds of tourists come to the temple on a daily basis. Yet, although it is a Buddhist temple, and as such one might expect the tourist to adopt a reverential gaze when visiting it, this essay shows how the tourist's experience is disconnected from the spiritual and becomes superficial. This disconnect is due in no small part to the highly decorated surfaces of the temple, which are overwhelming, plastic and undeniably strange for a Buddhist temple. The temple is not only highly decorated, but also regulated and restrictive. All visitors are monitored and surveilled to make sure they approach the space and the different buildings as they should, and therefore experience them as intended for maximum visual impact. Visitors therefore approach the temple as they would other simulated postmodern spaces available to tourists. Their experience of the surfaces is reinforced by the commercial aspect of material culture available in the temple gift shop, where other objects of similar artistic and decorative qualities, as opposed to religious paraphernalia, are available for sale. Although the artistic programme of Wat Rong Khun has a lot to offer when it comes to religious teaching and iconography, the temple is here analysed as a postmodern simulated space, a simulacrum reinforced by consumerism, of both the visual (overabundant decorative temple surface) and material culture (artistic prints available in the gift shop).
\end{abstract}

Keywords and phrases: postmodernism, Buddhism, neo-traditional art, simulated space, tourism 


\section{Introduction}

Wat Rong Khun is a small temple located in northern Thailand, outside of Chiang Rai. Since the commencement of its reconstruction in the 1990s (a reconstruction that is still underway in 2016), Wat Rong Khun is fast becoming an important tourist attraction in Thailand. In the early 2000s, on any given day, an average of 600 national and international visitors came to the temple, mostly due to its highly decorated buildings. Thai temples, especially of the Bangkok style, are often quite embellished. However, Wat Rong Khun is exceptionally and lavishly decorated, more so than other traditional Thai temples in the region.

There is no denying that the space of the temple offers the visitor a distinct experience, yet I contend that this experience is detached from the spiritual as a religious experience. Although a Buddhist temple, at first glance, it has more to do with a theme park that has Buddhism as its main attraction, than a space promoting spiritual enlightenment, inviting visitors to experience the temple with a reverential gaze (Urry 1995, 21).

In this sense, this article focuses on the tourist's experience of its space, rather than the temple's art historical, iconographic or religious meanings, or even local setting. ${ }^{1}$ Indeed, I contend that the temple is detached from its physical, religious as well as historical surroundings, to stand on its own. I argue that the temple is a themed space, a postmodern simulacrum, offering a postmodern experience similar to what Umberto Eco and Jean Baudrillard describe (Baudrillard 1994; Eco 1986). Although a Buddhist temple, and therefore a religious structure, in this essay, I contend that the space of this temple is comparable to other themed spaces visited by tourists, including Disneyland, the quintessential simulacrum (Munt 1994, 101). ${ }^{2}$ Compared to other researches on the simulated space, this article will pay particular attention to the artistic surface of the architectural structures, its plasticity and overwhelming decoration.

However, I also believe that it was not the intention of the artist to create such postmodern experience. On the contrary, the artistic style of the temple is firmly located within a nationalist modernist movement in Thailand, a neo-traditionalism. Yet, due to the exceptional decorative surface of the temple, I will argue that the modernist and nationalist discourse of the temple is no longer accessible to the viewer, leaving them with an overwhelming decorative surface devoid of meaning, leading to an uncanny experience of the space. Therefore, building on previous studies on postmodern spaces, this article will focus on how the artistic construct, most importantly the decorated surface, gives rise to a postmodern simulacrum. 


\section{Literature Review}

This article will pay particular attention to the tourist experience, an important and growing object of study in academia. Natan Uriely indicates that when it comes to postmodern tourism, scholars fall into two different groups (Uriely 1997, 982985). One group focuses on tourism as a new middle-class social practice looking to establish social differentiation and distinction from the decidedly commercial and mass-packaged ${ }^{3}$ tourism available today (see for example Munt 1994, Urry and Larsen 2011, 98-106; Nuryanti 1996; Sutton and House 2003). This type of tourism is often on the quest for the 'real' and/or the authentic, including an apparently culturally sensitive experience of the foreign.

Still according to Uriely, the second group of scholars investigating postmodern tourism does not look at tourism as a quest for the authentic or the real, let alone social elitism, but look at the commodification of the tourist experience through representations. Taking Baudrillard as a point of departure, many scholars look at the commodified space for tourists, not as a source of authenticity, but as a representation. Describing such investigation of the postmodern tourist space, Pretes $(1995,2)$ writes that: "Reality gives way to representation, the real is no longer meaningful or necessary. History, time, and space as aspects of culture, become commodities." Instead of looking at the space as a source of traditional culture, it is the experience of such space that becomes central to their analyses (see for example Pretes 1995; Sutton and House 2003; Baudrillard 1986 \& 1994; Eco 1986; Featherstone 2007, 67-68, 99-100). Typical simulated spaces would be the world fair (Urry 1995, 149, 179), the shopping mall (Woodward 1998, 45-56; Woodward, Emmison and Smith 2000, 339-354; Shield 1989, 147-164), the cosmopolitan urban space as well as the hotel (Jameson 1991), and of course the theme park, that is an artificially created space specifically for tourists (Pretes 1995; Baudrillard 1994; Eco 1986). These simulated spaces become worlds of their own, or microcosms (Woodward, Emmison and Smith 2000), where the 'rest' of the world is referenced, represented rather than used as point of departure (Urry 1995, 179). This article builds on this second type of scholarship. That is not to say however that regional or local practices are no longer investigated as sources of representations, indeed the representation could be one of tradition. An important work investigating local traditions, nostalgia of the past and spiritual performances as representations to be consumed is Rosalind Morris (2000).

Other scholars have also investigated religious experiences and spaces in relation to consumerism and the postmodern in Thailand. Jim Taylor (2008), in his book Buddhism and Postmodern Imaginings in Thailand, focuses mainly on the concept 
of urban Buddhism and the postmodern religious experiences and practices of Bangkok's growing middle class. In that respect, Taylor's work is typical, since simulated spaces are often associated with the experience of the urban space as well as the urban middle class (Cooke 1988; Dean 2000), and although not always studied from the perspective of tourism per se, these spaces are seen as sources of leisure for the contemporary flaneur, promoting consumerism. Furthermore, the consumption of both objects and images, or the surface, is an important part of the simulated postmodern space (Jameson 1991; Baudrillard 1986; Woodward 1998; Woodward, Emmison and Smith 2000; Pretes 1995).

Adding to these few studies investigating religion, representations and the postmodern experience, this article investigates a small, roughly 300 inhabitants (Gamache 2010, 206), local temple in northern Thailand as a simulated postmodern space. That is not to say however that the temple will be studied from a perspective of localism. Indeed as it will be explained in greater details later, there is a clear distinction between the spaces visited by the local villagers and the spaces visited by the tourists, both national and foreign.

This article will focus on the visitors' consumption of images and their experiences of the temple space. Following scholarship on the postmodern tourist experience, I use the term 'consumption,' not as a reference to the act of buying an object, but the process of consuming the representation, that is the association of signs, that is distinct from giving a 'real' meaning to an object or image (Pretes 1995, 2-4; Lane 2000, 74-75). Explaining this type of consumption, Pretes $(1995,2)$ says that: "the tourist consumes images or representations of a society; and any reality is obscured by many levels of representation. Therefore, the tourist is unable to penetrate any underlying reality, but must consume the representation, the sign, or the image of the touristic object." In our postmodern society, it is this association of signs which is now important and valued, not the potential meanings of the signs. In other words, these signs become empty, referring to other signs instead of referring to a stable concept of 'reality' or 'real' meaning in which authenticity might be located. This is true of scholars looking at art from a postmodern perspective as well. This article also differs from previous studies of the postmodern simulated space as it focuses on art as the main, though not the only, catalyst of this postmodern experience.

Generally, scholars looking at the postmodern in art either bring a celebratory look at art or one that proclaims the 'end' of art. The former group of scholars usually celebrates eclecticism, hybridity of form, creativity and plurality (Barry 2002). Such postmodern art often merges well-known styles, often traditional elements, in a new format, bearing little resemblance with the 'original' traditional source. 
The art is then disconnected from its original/traditional meaning and symbolism (Poshyananda 1992, 190-195). Related to this interest in reproduction loss/gain of traditional source is Walter Benjamin's important essay, The Work of Art in the Age of Mechanical Reproduction (2010).

On the other hand, scholars claiming the 'end of art' look at contemporary art and see its commodification, the proliferation of signs, the loss of 'pure' aesthetic, and conclude that 'art' as an identifiable construct is no longer possible. Art is now part of the everyday life, or, more precisely, everything in our daily lives has become art, an image, a sign, and therefore, art per se no longer exists (Baudrillard 1986, 14-19). ${ }^{4}$ Baudrillard calls this postmodern phenomenon 'transaesthetic' (Baudrillard 1994, 14-19). In this article, I will look at the temple and its art, not as a source of meaning, but I will look at it from the perspective of 'representation'.

\section{Neo-traditionalism}

As mentioned, the temple's decorative surface is one of the main catalysts of the tourist postmodern experience. Yet, the temple's artistic style, neo-traditionalism, is a modern style in Thailand. We therefore need to look at why neo-traditionalism, at least in this case, brings a postmodern experience of the space.

Art historian and curator Apinan Poshyananda describes early neo-traditional Thai art as the artistic movement that 'saved' modern Thai art, from the perceived banality of 'copying' Western styles (Poshyananda 1992, 68). ${ }^{5}$ Some observers of the 1960s and 1970s Thai modern art scene were questioning the apparent lack of local reference and content of the different artworks from the period (ibid.). Neo-traditionalism, on the other hand, offered a local 'flavour' from the beginning, usually by including some traditional elements in their paintings. The style quickly gained patronage and scholarly attention (Clark 1998, 73-75; Gamache 2010; Mashadi 1996, 65; Mukdamanee 2008, 141; Phillips 1992; Poshyananda, 1996, 1992).

One of the first important neo-traditional artworks is Panya Vijinthanasarn's, Defeat of Mara on the western wall of the bot at Wat Buddhapadipa in Wimbledon (Cate 2003, 37; Kositpipat, Panya and Sompop, 1987, 20-25). Wat Buddhapadipa was studied and described extensively by scholars of art history and a detailed analysis of the temple is beyond the scope of this article (Cate 2003; Poshyananda 1992, 199-200). Most notable for the purpose of this article, Panya's work gathered a lot of attention due to its eclecticism and destabilising representations. In these early experimental moments of neo-traditional art, Panya was bold and audacious (Poshyananda 1992, 199). On the wall, Vincent van Gogh, is found next 
to 17 th century British soldiers, bazookas, elephants, rockets, as well as historical figures fighting with bows and arrows, sci-fi Nazi soldiers and Leonardo's Mona Lisa, to name only a few of the anachronistic elements found on the wall. The reinterpretations of art history, history and religious texts using new visual elements while mixing different artistic styles, was impressive. The mural questions art itself, the relation between Eastern and Western artistic traditions and different aspects of reality (Gamache 2010, 162-165). The wall painting at Wat Buddhapadipa, most notably the Defeat of Mara by Panya Vijinthanasarn, shifted Thai art towards eclecticism, hybridity and postmodernism (Poshyananda 1992, 199-201).

Many artists, Chalermchai Kositpipat included, were inspired by Panya's artistic experiments, and transformed the visual aspects of their own works to resemble his. ${ }^{6}$ However, and very quickly, the content of Panya's work was forgotten. In other words, artists copied the style, or more precisely the juxtaposition of historical or traditional elements in a new contemporary setting. They now focus on its form rather than its content. Indeed Panya's painting at Wimbledon was an interpretation of traditional Thai art and this new type of representation of tradition was a great part of the visual appeal. Artists now copy the form, not because they want to question Thai art, but because the form has now become a signifier of modern Thainess.

In a way, the Thai neo-traditional project was so successful that it shifted, from an art-historical postmodern project to a modern one. Rather than questioning the concept of Thainess, it is now a symbol of Thainess, whatever it means. Neotraditionalism, almost victim of its own celebration and recognition, has now become an essentialist and institutionalised style. The signifier is now so strong that even its form seems to be secondary to its expression of Thainess. Clark (1998, $73,75)$ sees neo-traditional Thai art as:

A rough compromise between accepting the legitimacy of past forms and techniques and an attempt to reinvent the context from which that legitimacy is drawn. The definition of neo-traditional art involves a reinterpretation of the formal value systems that govern art, ones usually denoted by a set of style markers, or by technique or content ... Neotraditional art has seen several positions develop from which to assert its quest for legitimacy. One is that of nationalism, the claim to represent in a modern form the aesthetic values of a past but in away suited to modern conditions.

This description, more conceptual than formally descriptive, points to the difficulty of identifying modern neo-traditionalism as a specific and unique style. In fact, neo-traditionalism is today probably easier to describe as an artistic movement, 
rather than a particular visual style, one that is now different from Panya's first experiment at Wimbledon. While early neo-traditional art might have aspired to, or indeed inspired, postmodern experiences, the style has now become a modern movement promoting a strong and rigidly defined Thai identity based on conservative nationalist ideals (Poshyananda 1992, 199-200; Clark 1998, 73-75). Chalermchai himself, the artist behind Wat Rong Khun, sees neo-traditionalism as a nationalistic style, a style that would help differentiate and strengthen Thai identity or Thainess in the face of Western influence and global consumerism (Poshyananda 1992, 197; Cate 2003, 126). Interestingly, Chalermchai wanted Wat Rong Khun to be such an embodiment of this essentialist neo-traditionalism. ${ }^{7}$

Although an iconographic analysis of the temple is interesting, to look at the space from the perspective of the tourist gaze is also important and particularly relevant in this case. Indeed Chalermchai, helped with its reconstruction not only so that the villagers would have a bot or ubosot (main hall of a temple), but also so that it would become a tourist destination. Tourism, already very strong in Thailand, is seen here as a way to increase the country's reputation in the world, and as such, it is very successful. Promoted as a source of national pride and a modern national symbol, the temple has now become an icon in the province, and, to a certain extent, in the country itself (Kositpipat, 2005, 19-23). The temple is indeed identified by the Tourism Authority of Thailand as one of the destinations 'not to miss' in the greater region of Chiang Rai province (Tourism Authority of Thailand, 2014). On the popular tourist website 'TripAdvisor' the most uploaded photographs taken by tourists who visit the region are images of the temple, either the bot or images of its decoration. Although visits fluctuate throughout the year, for a two weeks period during the summer of 2007, I observed between 600 and 700 visitors per day. Most of them, two-thirds, were Thai, one-third were foreigners and the majority of all visitors were part of organised groups and/or family groups. Some foreigners had private tour guides (Gamache 2010, 69).

Interestingly, and although Chalermchai previously worked on the murals at Wat Buddhapadipa, to build such a large complex is very different from Chalermchai's previous neo-traditional artistic endeavours (Cate 2003; Gamache 2010). Because this article focuses on the tourist experience of the space, we need to describe this decorated space, including the buildings and their decorative surfaces, but also how visitors physically approach the temple.

\section{The Temple}

Wat Rong Khun was first constructed in the 1950s. It was then only one of many small village temples in Thailand. In the 1990s, the then 40 years old temple 
needed repair. The dining hall as well as the great gate were rebuilt, and under the guidance of Phra Khru Chakhriyanuyut, a herbal sauna was added for the treatment of drug addicts. However the main building, the bot or ubosot (Chairat, 2005, 73-77; Gamache 2010, 165), also needed repair, as it had become unsuitable for worship. The old bot or ubosot was therefore demolished in 1996 to make way for a new hall. Unfortunately, a year later, the financial crash of 1997 affected the whole of Thailand. The villagers no longer had the means to help with the reconstruction and the project was abandoned, leaving them bot-less. Because Rong Khun is his home village, Chalermchai decided to offer his services and help finish the work (Gamache 2010, 166; Sewatham and Soupara 2549/2005, 213). At this point, Chalermchai levelled the entire temple ground to make way for a grand artistic project dedicated to the three pillars of Thailand, that is the Nation of Thailand, Buddhism and the King (Wyatt, 1984, 216; Vella 1978, 139-140).

The new temple is indeed a massive enterprise, for which there is no equivalent in Thailand. ${ }^{8}$ The original temple was 4 rai or the equivalent of $6400 \mathrm{~m}^{2}$, which is rather conventional for a village temple. Chalermchai's vision is, however, quite large and 4 rai did not suffice. Surrounding rice paddies were therefore acquired and joined to the temple, which is now $10 \mathrm{rai}$ and 100 square $\mathrm{wa}$, or the equivalent of $16400 \mathrm{~m}^{2}$, a rather large temple in comparison to other village temples in Thailand (Gamache 2010, 166). It is important to note that Wat Rong Khun is still under construction and will probably be for a long time. In fact, Chalermchai has indicated that he will die before the temple is finished. It has become, according to the artist, his life project (Gamache 2010, 36). ${ }^{9}$

The temple ground is rectangular, with a walkway as its main east-west axis. The ground is then divided into three sections, two on the southern side of the walkway and one on its northern side.

\section{Three sections}

The temple currently has nine main buildings, three in each section and some other minor ones. ${ }^{10}$ These three main sections are the Karawat, the Sanghawat and the Buddhawat. The Karawat is the section for the laity, with a shop, a bathroom and a preaching hall. The Sanghawat, the section for the monks, has the crematorium, the $k u t i$ or the residence for the monks, and a hall of contemplation. The Buddhawat is the section for the Buddha, where we find the bot, the pavilion of relics and the pavilion of images. These three constructions in the Buddhawat are the equivalent of the three main buildings, other than the kuti, found in Buddhist monasteries in Southeast Asia, which are the bot or ubosot (Chihara 1996, 39-43; Sthapitanonda and Mertens 2005, 82), the vihan or here the pavilion of images (Chihara 1996, 
34-37) and the chedi or stupa, or here the pavilion of relics (Chihara 1996, 37-39; Sthapitanonda and Mertens 2005, 94). Not all buildings in the first two sections are finished and many buildings are still lacking their ornaments. The already decorated buildings show reflective surfaces due to the addition of shards of mirror on stucco and elaborate stylised decorations, with tendrils and arabesques also in stucco. While Thai temples are often highly decorated, especially the temples of the Bangkok style, the embellishments at Wat Rong Khun are very different from other traditional Thai temples. The visual effects of the decoration will be studied in more details later.

The Karawat, or section for the laity, is the first section people experience when they enter the temple ground. Two of the buildings in this section are white, while the bathroom is gold in colour. There are also secondary structures, such as a golden fountain, which is found at the junction between the Karawat and the Buddhawat (Gamache 2010,142). There is also a large covered area where people can rest and hide from the sun. The Karawat is the first section the visitors go through, but is also the only way for people to currently leave the temple. It is therefore often crowded with people both going in and out of the temple ground.

The Sanghawat is further along the path from the Karawat and is the section with the most construction and decoration still to be added. Nevertheless, the kuti was the first building constructed by Chalermchai, as the monks in residence needed a place to stay. The current state of the kuti is a good indicator as to how difficult it is to maintain white stucco in Thailand. Although the buildings are supposed to be white in colour, mold and general decay are found on the structures which now look rather dirty, if not grey.

The third section, the Buddhawat, takes up the entire northern section of the temple and is separated from the Karawat and the Shangawat by a white picket fence. This section is comprised of three main buildings, which are the bot, the pavilion of relics and the pavilion of images. ${ }^{11}$ They are organised in a straight line, and are separated from each other by two bridges. There are however a number of secondary constructions creating an elaborate and highly decorated ensemble. The Buddhawat includes fountains, pools of water, free standing statues, a few wellkept trees, bridges, one in front of the bot and one linking the pavilion of images and the pavilion of relics, ${ }^{12}$ as well as other decorative elements.

\section{Regulation}

To reach the Buddhawat, visitors have to go through the shaded area of the Karawat and as mentioned earlier, the Karawat, especially the shaded area is often crowded. 
Furthermore, if one stands under the shaded area of the Karawat, the bot inside the Buddhawat is not visually available as it is hidden by trees and the golden fountain. However, once we pass the white picket fence dividing the Karawat from the Buddhawat, the place opens up. The bot, further away in the Buddhawat, is now visually available, as no tree or decoration hinder the visitor's field of vision..$^{13}$ The experience of the space is therefore carefully regulated so that people experience it from a specific vantage point, but also experience a certain openness or 'release' when entering the space of the Buddhawat. This effect is intentional and the space was carefully created for the visitors.

Furthermore, on the temple ground, including the Buddhawat, trees are found in a way which might appear random, yet they were all carefully selected and planted where they would give the desired effect. For example, most of the trees are found along the path dividing the temple on its east-west axis, not only providing shade, but also blocking the view of the bot when standing in the southern section of the temple. These trees indeed reinforce the spatial separation of the Buddhawat from the rest of the temple, making sure the visitors will experience the open space of the Buddhawat as it is intended.

Adding to the 'natural' effect of the temple, flower baskets are also found along the path. Furthermore, orchids were grafted to trees, at eye level, as part of a beautifying effort. Interestingly however, the natural aspect of the temple is visually not sustainable and it becomes obvious that the whole natural effect is man-made. For example although orchids are found wild in northern Thailand, they are usually not found so low to the ground.

Furthermore, the temple employees seem to constantly be working to keep these natural elements available. The trees are groomed, the lawn is cut, the path is cleared of dead leaves and the architectural structures are cleaned in an effort to keep the natural appeal of the temple. In other words, the workers are constantly working against nature, trying to keep it at bay, so to keep the temple's man-made natural appeal. It becomes apparent however that the visual effect is difficult to sustain. Another example already mentioned would be the impossibility of maintaining the 'whiteness' of the temple, as mold and water stains have already dirtied the different buildings, especially the kuti, beyond their original pristine white. In other words, the temple is disconnected from its environment, to the point of being difficult, if not impossible, to sustain.

Furthermore, this particular experience of nature, that is a 'controlled' one, is only experienced when one is on the temple ground. As soon as we look at the temple from 'outside' of its perimeter, we realise how at odd the temple is from its 
surrounding. Indeed northern Thailand is known for its mountains, rice paddies and green forests. The temple, although not surreal, offers an interesting spatial experience, as it is clearly separated from the outside world, becoming its own hyperspace. This is particularly strong when one enters the Buddhawat.

This regulation of the Buddhawat is further emphasised as the visitors are guided, even monitored and surveilled, by temple workers so they do not venture outside of their designated areas or do not take the path the 'wrong' way. No tourist is left unattended, their experience of the temple and therefore its space is carefully regulated. Regulation and surveillance are also identified by Woodward, Emmison and Smith $(2000,339)$ as important determinant of postmodern spaces. For the visitors to experience the space as intended, nothing is left to chance, or indeed nature.

\section{Spatial Experience and the Surface}

When the visitors first enter the Buddhawat, the space opens up to a fantastical and highly decorated world. An important characteristic of this section, and indeed of most of the temple, is the heavy use of white for the decoration of its buildings, including the bot. ${ }^{14}$ Indeed, on the internet, the temple is often referred to as the White Temple. However, as mentioned earlier, due to its geographical location, the whiteness of the temple is hard to maintain, mainly due to water stain and mold. Though the surface of the temple is no longer as pristine as it was intended, it is nonetheless quite impressive. Indeed the Buddhawat, especially the ubosot or bot, is heavily decorated, with multiple arabesques, tendrils and fantastical animals. The walls and arabesques made of stucco are further decorated with shards of mirror. These shards, found on nearly all surfaces, give an almost iridescent quality to the bot. Yet the overall effect is not necessarily light. On the contrary, the sheer number of these ornaments renders the bot quite heavy. The numerous decorations also make it difficult to differentiate specific details from the whole. Only when larger ornaments and decorations are at eye-level can one focus on them. When the ornaments are further away, the overall surface takes precedent. It is therefore important to describe some of the larger decorations found at eye-level and the overall visual effect of the surface.

Once they cross the gate into the Buddhawat, the visitors find themselves on a path leading to the first bridge, that is the bridge of rebirth (Sewatham and Souksawat 2548/2004, 216; Gamache 2010, 174). Before reaching the bridge however, they need to walk over Mara's mouth (Bruswell Jr. 2004), ${ }^{15}$ in which you can find hundreds of hands as well as a few feet and faces of people damned to hell. These hands and feet are close to the visitors, making this a physical and graphic 
journey through hell. As observed during the summer of 2007, this section of the temple attracts a lot of attention. This graphic representation is akin to other tourist attractions where the visitor is physically transported or experiencing a different simulated world.

Once the visitors have walked over hell, they then pass two stylised demons, one on each side of the bridge of rebirth. Of course, statues of demons are common occurrences in Thai temples, however those demons are different from the prevailing stylised demons found on the ground of large traditional Thai temples. The demons at Wat Rong Khun are closer to graphic novels characters than traditional Thai art. This description of the first decorations encountered by the tourist supports and strengthens the experience of the temple as a themed space, one that would be created as entertainment for visitors.

Following the only path available to them, the visitors cross the bridge of rebirth and find themselves in front of the most decorated building on the temple ground, the bot. The building is so heavily decorated, that it becomes difficult to focus on any specific element with visual accuracy. For example, the fantastical animals on the pan lom (Gamache 2010, 177-178) are difficult to identify as they themselves look like the non-zoomorphic stylized arabesques found all over the temple. These elements are exaggerated to the point of distortion, resulting in a plastic and stylised, almost forced, and definitely unnatural, decorative surface. Worst, the numerous decorations and heavy treatment of the surfaces make it difficult for the viewers to settle on any given detail without being overwhelmed, forcing them to return to the general surface and overall representation. In other words, what the visitors can access is the surface of the temple. The small details, although interesting in themselves, are lost in a sea of stylised features of an extravagant surface. Even the three dimensionality of the numerous finials is undermined by their surfaces. Indeed the details are so numerous that it becomes difficult to see them in space. In other words, it becomes difficult to distinguish which tendril is attached to which finial, or indeed where the finials start or end. Visually, the decorations seem to be part of one elaborate surface, rather than having a clear three-dimensionality. The space becomes extravagantly decorated, yet this decoration stays superficial. Visitors neither look for meaning or visual details. The heaviness of the decoration is overwhelming, leading the visitors to experience the Buddhawat on a superficial level, that is its overall decorated surface, only momentarily gazing at details without being able to focus on specific ones, let alone follow the complex iconographic programme.

That is not to say however that the Buddhawat is not an interesting iconography. However, if the visitors are not helped pinpointing the elements holding symbolic 
meanings as well as guided through the complex symbolism of the identified details, their specific meanings and Buddhist teachings will be lost on them. Even for a Thai visitor, the complex programme is far from obvious. For example, the individual path leading to the bot represents the Theravada Buddhist beliefs that reaching Nibbana (Nirvana) ${ }^{16}$ is an individual endeavour (Kositpipat 2005, 25; Thip 2009); the leaf-like patterns at the top of the bridge of rebirth represent Mount Meru, while the recessing fountain-like structures found in the pool under the bridge represent the mountain range surrounding it (Kositpipat 2005, 27; Thip 2009); the four small human figures in the middle of the four flame-like structures at the corners of the bot represent the Buddha's early disciples (Thip 2009, 27); the different roof finials in the shapes of four stylized animals found at the top of the bot represent the four elements: fire, water, air and earth (Kositpipat 2005, 29-30). These are only a few examples of the heavy iconography created by the artist.

Yet the visitors cannot easily identify the decorations with specific iconography, let alone read their intended meanings. As the heavy decoration is used for visual effects rather than articulation of meaning, the visitor, unaware of the strong and detailed symbolism, is trying to negotiate a very difficult space, a space lost in semiotic. The unguided visitors, unable to see, let along read artistic details, are left with the experience of the space itself, a space which is separated from its surrounding and context, one that is plastic, man-made, restrictive, and superficial, yet stimulating and also appealing, due to its visual quality and strange familiarity. This is due to the familiarity tourists have of themed spaces, as they are clearly created specifically for tourists by tourists.

Therefore, and though the religious nature of the space is undeniable, after all it is a Buddhist temple, it is primarily experienced as something else than a spiritual space from a religious perspective, one we would approach with a reverential gaze. Indeed once the gate and the white picket fence separating the Buddhawat from the rest of the temple is crossed, it becomes a space of its own, a themed space with Buddhism as its subject. Partly due to its 'dream-like' quality, isolation from its surroundings, highly stylized and plastic surfaces, and abundant decoration, the visitors come to the temple as they would a simulated space, such as a theme park (Taylor 2008, 83). In his book Consuming Places, Urry $(1995,149)$ identifies the shopping malls and the world fairs as examples of simulated realities he calls 'global miniaturisations'. Disney World, especially Epcot, is also such an example. In these simulated spaces, the visitors collect and consume empty signs of different cultures represented in a space constructed for them. The same happens at Wat Rong Khun, here with Buddhism, rather than world cultures. Furthermore, as Pretes explains, simulated spaces solely created as tourist attractions are often playing on nostalgia, either they be representing the past or the future (Pretes 1995, 4). 
Here the space is ethereal and fantastical, as it is supposed to represent a Buddhist heaven or even Nirvana (Gamache 2010, 158-161). The simulated space does not bridge the past, or future, with the present, but bridges two different realms. This Buddhist space becomes a spectacle, a physical space to be enjoyed and consumed. This consumption is not only experienced visually, but also materially. The visual consumption and the material consumption work with each other, creating a simulacrum.

\section{Commodification}

Though it is true that many temples, especially temples visited by tourists, will have gift shops, the goods on sale are usually religious in nature, for example amulets, statues of the Buddha or books on Buddhism. ${ }^{17}$ At Wat Rong Khun, the Karawat gift shop sells printed copies of the artist's paintings, his numerous biographies, as well as t-shirts and postcards with images of the temple itself. Books on Buddhist teaching, statues of the Buddha and other religious objects commonly found at other Buddhist temples are nowhere to be found. The gift shop is halfway between a museum gift shop, with art reproductions and coffee table books, and a gift shop one finds at any tourist attraction, with its numerous t-shirts, caps, keychains and other trinkets. But most importantly for this analysis, printed copies of Chalermchai's original works are available for purchase.

Indeed as mentioned earlier, Chalermchai, the artist responsible for the temple, is an important and recognised neo-traditional artist, most commonly known for his acrylics on canvas. Interestingly, the temple is stylistically similar to Chalermchai's paintings of the 1990s and early 2000s (Gamache 2010, 191-199; Collins 1998, 304-311). ${ }^{18}$ Indeed he used the same recognisable, highly stylised and plastic ornamentations described earlier, in both his paintings and the temple. At the gift shop, we can find the prints of twenty or so paintings by the artist. The original paintings were, in other words, transformed into affordable souvenirs.

Interestingly, although there are around 20 different prints for sale, they are all very similar to one another, most of them representing the same type of Buddhist imagery, that is to say a highly decorated, pastel coloured representation of celestial abodes or different types of celestial transportations. The original paintings are not available for sale, nor is it necessarily obvious for the visitors that the prints are copies of actual paintings, nor indeed that these representations are based on religious texts describing Buddhist heavens. What is available to the visitors is the visual aspect of these reproductions, which closely resembles the temple they just visited or are about to visit. The prints reinforce the imagery of the temple, and vice versa. Following Benjamin (2010), due in part by this visual reproduction, 
the temple and its artistic elements are further separated from potential spiritual, historical or even traditional readings. The temple's referent, Nirvana, is lost on visitors. ${ }^{19}$ What is available is the artistic 'bubble' that is now the Buddhawat with its superficial, commodified and highly carnivalesque space. The temple becomes a world of its own, a self-referencing spectacle.

This repetition of the stylistic surface, this surface without a model, creates an experience of an "external effect of resemblance" (Smith 2006, 102). The boldness of its extravagance implies a depth, a spiritual dimension, which is not in fact there. "It is precisely because he [the viewer] cannot master them [the implied] that he experiences an impression of resemblance" (Deleuze, quoted in Smith 2006, 102). One is dazzled by the effect of the temple, its extravagance, an extravagance that is repeated everywhere on its ground, even in the gift shop. In this sense, the temple is a powerful simulacrum in a Deleuzian sense (Deleuze, 1983; Smith 2006).

Although the intended meaning by the artist is unavailable, what is available is no less powerful however. What is available, to all visitors, is a superficial, yet highly stimulating, experience based on consumerism: consumption of the images but also the objects for sale. This is a crowd experience as defined by Don Slater (1993), one experienced in a contained space, yet created from an intensified representation that becomes highly stimulating. Here, it draws the visitor into an almost out of this world experience, a spiritual experience not based on faith or religious Buddhist texts, but based on consumption. Buddhism here is replaced by consumerism, of the image and the objects in the gift shop, as the source of personal satisfaction of desire, in other words, a new spirituality satisfied by consumption.

Wat Rong Khun is not the only simulated, but also commodified, 'religious' space in Thailand. In his book, Buddhism and Postmodern Imaginings in Thailand, James Taylor looks at Wat Sanam Chan, which shares similarities with Wat Rong Khun. In his analysis of Buddhism and postmodernism in Thailand, Taylor looks at Sanam Chan as a simulated space, which he compares to other "commercial hyperspaces of desire" (Taylor 2008, 84), such as Dream World in Bangkok (DreamWorld 2012) and also Disneyland.

Sanam Chan is a temple situated just outside of Bangkok, in Chachoengsao province. In the 1990s, it was best known for what Taylor $(2007,3)$ calls its 'Superman' Buddha, which, as the BBC reported in an article on 17 July 1998, was deemed inappropriate by the Thai Education Minister (Taylor, 2008, 78). The temple itself is described by Taylor as being 'carnivalesque', kitsch and commercial, something which is also true of Wat Rong Khun. At Wat Sanam Chan, one can find numerous statues of religious figures such as Hindu gods and the Mahayana 
Goddess of Mercy Kwan Im, something not entirely conventional for a Theravada Buddhist temple (Taylor 2008, 81). There are also wall paintings depicting local spirits, magical monks, and wells of fortune (Taylor 2008, 81; Taylor 2007, 6-7). Describing Wat Sanam Chan, Taylor $(2008,83)$ says: "It is a place of readily and immediately accessible commodified sacra and where feeling is so important."20 The two temples, although visually quite different, promote similar experiences. Although at Wat Rong Khun, there is the added layer of commodification of Fine Arts to the already mentioned commodified sacra.

Wat Rong Khun is indeed a fantasy place of artistic extravagance where we can find commodified art for national and international tourists. ${ }^{21}$ Visitors are attracted to the temple because of the unconventional artistic project of a known neotraditional artist (at least for the national visitors), rather than being attracted to the temple because of the temple's sanctity or its monks' reputation as spiritual leaders. Again, Buddhism is here transformed into consumerism. The temple is consumed at the 'visual' level, that is the consumption of its space and surfaces, which then leads to the consumption of objects, that is of material culture (Urry 2005, 22-23), a miscellany of commodified art and cheap souvenirs.

\section{Conclusion}

Though one does not necessarily readily associate consumerism with Buddhism, there is an undeniable commercial aspect to the temple. ${ }^{22}$ While Chalermchai saw neo-traditional art as a style to counter western consumerism, the temple could not probably survive without its commercial aspect, since the money generated from the gift shop goes into the temple's construction (Gamache 2010, 165; Chairat 2005, 73-77). ${ }^{23}$ But most importantly, consumption is now an intricate part of the visitor's experience, both material and visual. Although the space started as a unique modern artistic experiment and project, it has now become strangely familiar, a themed space similar to other themed spaces, experienced through consumerism rather than a knowledge of Buddhism or art history. In other words, the stylisation and heaviness of the decoration transform this space from the intended modern one, to a postmodern simulated one that enthrals and amazes, where desires are answered through consumption rather than religious teaching that might lead to spiritual introspection, or indeed a source of art historical and iconographic study.

Due in no small part to the fantastical and dream-like quality of its space, Wat Rong Khun is a growing tourist destination in Thailand, for both national and international tourists alike. The temple started as a grand artistic project that would indeed bring tourism to the region. Although the temple was created with a complex iconography, the stylistic treatment of its surface and overabundance of decorative 
material make it impossible for the tourists to identify specific iconographic details. The strangeness, due partly to the strong plasticity and surreal quality of its decorative program, is therefore transformed into a familiar space recognised by tourists, that is a simulated space similar to a theme park. In other words, the obviously strange and fantastical become familiar.

Following Jameson, Woodward says that "perhaps above all, postmodern spaces encourage, and indeed celebrate, the consumption of both commodities and images" (Woodward 1998, 48). This is the case of Wat Rong Khun, where the treatment of its artistic surface promotes a consumption of its image, rather than a religious introspection. Although the temple is obviously a religious structure, the tourist experience is disconnected from the religious. Granted, a religious follower could argue that Buddhist Nibbana (Nirvana) does exist, however if it does, it does not exist on this physical plane of existence, nor is its potential actual imageries available to copy. ${ }^{24}$ Therefore, the artworks and the temple are artistic interpretations and physical representations of religious concepts, without available originals. Yet for the visitors, the religious aspect is lost in the spectacle of the space itself, reinforced by the commercial aspect of the available souvenirs and commodified art. The temple itself is now disconnected from its religious justification and teaching to become, following Baudrillard, a simulacrum (Baudrillard 1994; Lane 2000, chap 5). Interestingly, this visual consumption, might not last at Wat Rong Khun. The visual appeal of the temple, that is the quality of its surface, including the whiteness of the construction, is unsustainable. It will be interesting to see if, in the future, the simulacrum is sustained, once nature reclaims the space.

\section{Notes}

1. For an iconographical and art historical analysis of the temple, see Gamache (2010).

2. Disneyland is indeed often referenced by scholars working on postmodern tourism, leaving Munt to identify it as the "quintessential postmodern experience".

3. Mass-packaged here refers to organised tourism, such as group tours available with tourist agencies, focusing on essential tourist attractions. An example would be the guided museum visits that only focus on a few masterpieces.

4. If we push this concept further, it announces the 'end' of art, where aesthetic judgment, value and taste no longer exist.

5. Early Thai modern art was seen by some as merely copying Western modern art. However, Thai artists were obviously experimenting and were not merely copying. Their works were more akin to mimicry of Western modern movements, yet the Thai audience focused on its apparent 'lack' of Thainess. 
6. The similarities between Panya's Defeat of Mara in Wimbledon and Chalermchai's Defeat of Mara at Wat Rong Khun is striking. Although in none of the publications available at Wat Rong Khun is Wat Buddhapadipa acknowledged as a source of inspiration, the resemblance is too striking not to mention here.

7. See Gamache (2010) for an analysis of the temple as an essentialist and nationalist project.

8. This is not to say however that Chalermchai is the only artist involved in the construction of Buddhist temples in Thailand. Wat Pa'O Ram Yen, also on the outskirt of Chiang Rai city is another good example (Gamache 2010).

9. The temple was also damaged in an earthquake that affected northern Thailand on 5 May 2014. The interior of the temple was damaged, including the wall paintings. However, it is important to note that even without the earthquake, Chalermchai claimed that this project would still be under construction after his death.

10. The overall division of the temple ground into three sections is at odd with tradition, as a temple is usually divided in two, with the Buddhawat and the Sanghawat (Gamache 2010,102).

11. These two buildings replace the traditional chedi and vihan respectively. Vihan are great halls while chedi are usually, at least in Thailand, massive yet solid structures one cannot enter.

12. The bridge in front of the bot is called the bridge of rebirth while the celestial bridge is between the pavilion of relics and the pavilion of images.

13. It is important to note that the bot was visually available from outside the temple ground. However, people did not have access to the space per se, as a fence and a trench separated them from the Buddhawat. In this section, I focus on the spatial experience of the Buddhawat when one crosses into the fenced and protected area of the temple.

14. Red was used for some elements, such as a skull, in the gapping mouth of Mara.

15. According to Buddhist texts, Mara tried to stop Buddha from reaching enlightenment. He is an embodiment of greed and delusion, among other things, which block people from reaching enlightenment.

16. It is not the goal of this article to analyse the validity of these symbols and/or iconography. This iconography was either directly explained by the artist himself in the different publications available in the gif -shop or analysed in other works.

17. See Taylor (2008, 65-87) for an interesting analysis of low-cost material culture on sale on temple ground.

18. In another work, I already looked at these paintings as artistic interpretations of religious Pali texts describing the different Buddhist heavens and their rewards. Interestingly, Chalermchai intended the Buddhawat as a representation of Nirvana (Gamache 2010, 191-199). To represent Nirvana as an actual physical space, on earth, is controversial. However, the visitors are not aware of this controversy. 
19. See Gamache (2010, 158-161). Indeed Chalermchai has painted Nibbana (Nirvana) a few times before creating the temple. While his paintings of different Buddhist heavens are pastel in colors, he usually represents Nirvana in white. Representing Nibbana in actual, physical form, is controversial, at least from a religious perspective. If visitors were aware of the debate and his different representations of heavens and Nibbana in his art, one could enter an interesting religious debate on the issue of Nibbana and its representation in material form.

20. Italic is Taylor's.

21. Yet, while doing field work in the region in 2003, it became evident that the village inhabitants were not using the space the same way the tourists were using it. If local villagers came to the temple, they were coming in the morning, to give offerings to the monks, or in the afternoon, bypassing the Buddhawat entirely and going directly to the Sanghawat to meet with the monks.

22. See Taylor (2008) for an important analysis of postmodern Buddhism, including different commercial aspects of Buddhism in our postmodern era.

23. It is important to note that the artist has invested a great amount of his personal money in the project.

24. Religious Pali texts do describe heavenly abodes however and there is an interesting relation between these texts and the paintings. Although the relation between the religious texts is interesting, from the tourist's perspective, this iconography is, once again, lost.

\section{References}

Anderson, B. 1991. Imagined community. London and New York: Verso.

Barry, P. 2002. Beginning theory. An introduction to literary and cultural theory. Manchester: Manchester University Press.

Baudrillard, J. 1986. Amérique. Paris: Grasset. 1994. Simulacra and simulation. Ann Arbor: University of Michigan Press.

BBC World: Asia-Pacific. 1998. Thailand's unsuitable statue, http://news.bbc.co.uk/2/hi/ asia-pacific/134631.stm (accessed 26 November 2014).

Benjamin, W. 2010. The work of art in the age of mechanical reproduction. New York: Prism Key Press.

Bruswell Jr., R.E. 2004. Encyclopedia of Buddhism (e-book). Farmington Hills: Thomson/ Gale.

Cate, S. 2003. Making merit, making art: A Thai temple in Wimbledon. Honolulu: University of Hawai'i Press.

Chairat, D. 2005. The history of Wat Rong Khun. In Creating Buddhist art for the land, trans. Malithat Promathatavedi; eds. Sewatam, Tophong and Supatra Suksawat. Bangkok: Amarin.

Chihara, D. 1996. Hindu-Buddhist architecture in Southeast Asia, trans. Rolf W. Giebel. Leiden, New York and Köln: E.J. Brill. 
Clark, J. 1998. Modern Asian art. Honolulu: University of Hawai'i Press.

Collins, S. 1998. Nirvana and other Buddhist felicities. Utopias of the Pali imaginaire. Cambridge: Cambridge University Press, https://doi.org/10.1017/ CBO9780511520655.

Cooke, P. 1988. Modernity, postmodernity and the city. Theory, Culture and Society 5: 475-492, https://doi.org/10.1177/0263276488005002016.

Dean, M.J. 2000. The postmodern urban condition. Oxford and Malden: Blackwell.

Deleuze, G. 1983. Plato and the simulacrum, trans. Rosalind Krauss. October 27: 45-56.

Dream World. 2012. http://www.dreamworld.co.th/panoramic/en/.

Eco, U. 1986. Travels in hyperreality, essays. San Diego, New York and London: Harcourt. Kindle edition.

Featherstone, M. 2007. Consumer culture and postmodernism. Los Angeles: Sage Publication.

Gamache, G. 2010. Between localism and nationalism: Two contemporary examples of Thai temples art and architecture in northern Thailand. PhD diss., University of Victoria.

Jameson, F. 1991. Postmodernism, or, the cultural logic of late capitalism. Durham: Duke University Press.

Kositpipat, C. 2005. Creating Buddhist art for the land. Bangkok: Amarin.

Kositpipat, C., Panya V. and Sompop B. 1987. The mural paintings of Wat Buddhapadipa, trans. Mira Kim Prachabarn and Pongsak Kanjanakpandh. Bangkok: Khana Chittrakon Asasamak.

Lane, R.J. 2000. Jean Baudrillard. London and New York: Routledge. Kindle edition.

Mashadi, A. 1996. Brief notes on traditionalism in modern Thai art. In Modernity \& beyond: Themes in Southeast Asian art, ed. Subapathy. Singapore: Singapore Art Museum.

Morris, R.C. 2000. In the place of origins. Modernity and its mediums in Northern Thailand. Durham and London: Duke University Press.

Mukdamanee, V. 2008. Development of contemporary art in Thailand. In Educating in the arts, ed. L. Joubert. Springer: Dordrecht, https://doi.org/10.1007/978-1-4020-63879 9.

Munt, I. 1994. The 'other' postmodern tourism: Culture, travel and the new middle class. Theory, Culture \& Society 11(3): 101-123, https://doi.org/10.1177/026327694 011003005.

Nuryanti, W. 1996. Heritage and postmodern tourism. Annals of Tourism Research 23(2): 249-260, doi: 0160-7383(95)000.

Phillips, H.P. 1992. The integrative art of modern Thailand. Berkeley: Lowie Museum of Anthropology, University of California.

Poshyananda, A. 1992. Modern art in Thailand. Nineteenth and twentieth centuries. Oxford and New York: Oxford University Press.

1996. Contemporary Thai art: Nationalism and sexuality à la Thai. In Traditions/ Tensions. Contemporary art in Asia, ed. A. Poshyananda. New York: Asian Society Galleries.

Pretes, M. 1995. Postmodern tourism. The Santa Claus industry. Annals of Tourism Research 22(1), doi: 0160-7383(94)00026-3. 
Sewatham, T. and Souksawat. 2548/2004. ผมวาดชีวิตผม/The drawings of my life. Bangkok: Amarin Publication.

Sewatham, T. and Soupara. 2549/2005. ผมวาดชีวิตผม/The drawings of my life. Chiang Rai: Wat Rong Khun.

Shield, R. 1989. Social spatialization and the built environment: The West Edmonton Mall. Society and Space 7: 147-164.

Slater, D. 1993. Going shopping. Market, crowds and consumption. In Cultural reproduction, ed. C. Jenks. London and New York: Routledge.

Smith, D.W. 2006. The concept of the simulacrum: Deleuze and the overturning of Platonism. Continental Philosophy Review 38: 89-123, https://doi.org/10.1007/ s11007-006-3305-8.

Sthapitanonda, N. and Mertens, B. 2005. Architecture of Thailand. A guide to traditional and contemporary forms. Bangkok: Asia Books Co. Ltd.

Sutton, P. and House, J. 2003. The new age of tourism: Postmodern tourism for postmodern people? http://www.arasite.org/pspage2.htm (accessed June 2014)

Taylor, J. 2007. Buddhism, copying, and the art of the imagination in Thailand. Journal of Global Buddhism 8: 1-19, http://www.globalbuddhism.org/8/taylor07.htm. . 2008. Buddhism and postmodern imaginings in Thailand. Farnham and Burlington: Ashgate.

Thip, K. 2009. Wat Rong Khun, Chiang Rai, trans. Milathat Promathataved. Chiang Rai: Wat Rong Khun.

Tourism Authority of Thailand. 2014. Recommended Chiang Rai. http://www. tourismthailand.org/About-Thailand/Destination/Chiang-Rai

Uriely, N. 1997. Theories of modern and postmodern tourism. Annals of Tourism Research 24(4): 982-985, https://doi.org/10.1016/S0160-7383(97)00029-7.

Urry, J. 1995. Consuming places. London and New York: Routledge. 2005. The 'consuming' of place. In Discourse, communication, and tourism, eds. A. Jawoski and A. Pritchard. Clevedon: Channel View Publications.

Urry, J. and Larsen, J. 2011. The tourist gaze 3.0. Los Angeles, London, New Delhi, Singapore and Washington DC: Sage.

Vella, W.F. 1978. Chaiyo! King Vajiravudh and the development of Thai nationalism. Honolulu: University of Hawai'i.

Woodward, I. 1998. The shopping mall, postmodern space and architectural practice: Theorizing the postmodern spatial turn through the planning discourse of mall architects. Architectural Theory Review 3(2): 45-56, https://doi.org/ 10.1080/13264829809478344.

Woodward, I., Emmison, M. and Smith, P. 2000. Consumerism, disorientation and postmodern space: A modest test of an immodest theory. British Journal of Sociology 51(2): 339-354, https://doi.org/10.1111/j.1468-4446.2000.00339.x.

Wyatt, D.K. 1984. Thailand, a short history. New Haven: Yale University Press. 